\title{
RELATIONSHIP BETWEEN FUNCTIONAL LIMITATIONS OF THE LOCOMOTOR SYSTEM AND PERFORMANCE IN JUDO
}

\author{
DARIUSZ BOGUSZEWSKIㄴ, MAŁGORZATA BUDA², JAKUB GRZEGORZ ADAMCZYK³, \\ DARIUSZ BIAŁOSZEWSKI ${ }^{1}$ \\ ${ }^{1}$ Medical University of Warsaw, Second Faculty of Medicine, Department of Physiotherapy, \\ Division of Rehabilitation \\ 2Doctoral Studies, Józef Pitsudski University of Physical Education in Warsaw, Faculty of Physical Education \\ 3 Józef Pitsudski University of Physical Education in Warsaw, Faculty of Physical Education, \\ Department of Sport Theory
}

Mailing address: Dariusz Boguszewski, Medical University of Warsaw, Division of Rehabilitation, 2c Księcia Trojdena Street, 02-109 Warszawa, tel.: +48 22 5720920, fax: +48 22 5720934, e-mail: dboguszewski@wum.edu.pl

\begin{abstract}
Introduction. The high demands imposed by judo with regard to physical fitness can predispose athletes practising this sport to injury. The aim of the current study was to determine the relationship between the degree of functional limitations and performance outcomes in judo athletes. Material and methods. The study involved 23 judo athletes aged 17-27 years. For the purpose of carrying out comparative analyses, the judokas were divided into two groups according to their level of achievement. The first group consisted of medallists in international tournaments and Polish championships, and the second group was composed of non-medallists. The research tool used was the Functional Movement Screen test battery, which included seven exercise tests whose performance was rated on a scale from 0 to 3. Relationships between variables were assessed using Spearman's rho correlation coefficients. Inter-group differences were determined by means of the Mann-Whitney U test, and differences between the left and right side of the body in bilateral tests were examined using the Wilcoxon test (statistical significance was set at $\mathrm{p} \leq 0.05)$. Results. The total score for the FMS test was significantly higher $(\mathrm{p}<0.05)$ in judo athletes who had a higher level of achievement. Scores below 14 points, which were indicative of high susceptibility to injury, were received by two athletes from the group of medallists and 8 non-medallists. Major asymmetries were not found in the subjects; significant differences were observed only in the shoulder mobility test in senior judokas $(\mathrm{p}<0.05)$ and non-medallists $(\mathrm{p}<0.01)$. Conclusions. Judo athletes who had better performance outcomes in competitions had higher scores in the FMS test. Functional limitations can have an impact on the outcomes of performance in judo; their degree is indicative of the quality of the movement as well as of susceptibility to injury.
\end{abstract}

Key words: judo, FMS, injury prevention, functional assessment

\section{Introduction}

Sports training is aimed at the development of muscle groups and motor skills that are the most useful from the point of view of competing in a given sports discipline or event. However, sometimes placing an excessive load on one element of the locomotor system causes an imbalance between its parts [1-3]. That is because muscles work together in coordinated patterns when a given type of movement is performed. Some muscle groups have a tendency to initiate the movement, whereas others play a stabilising role. If these patterns are disturbed, this can cause overloading, resulting in injuries to the locomotor system $[4,5]$. A key part of injury prevention is implementing adequate training, which should be adjusted to the needs and skills of an individual athlete. It is also important for athletes to recover between training sessions and competitive events, which is when intense physical activity is performed [6-8]. The types of exercise that play a major role in preventing injuries include core stability exercise, eccentric training, plyometric ex- ercise, dynamic stability exercise, and proprioception training $[9,10]$.

Combat sports are a discipline where two contestants fight with each other using techniques that have a direct impact on their opponent's body in order to subdue them. The fight involves using such techniques as, among others, grappling or throwing (judo, aikido, and wrestling) as well as striking (kickboxing, boxing, and taekwondo) [11]. In combat sports, general training is aimed at helping motor skills develop in an optimal way. As research has shown, elite athletes have a similar level of motor skills, but the level of their physical fitness is significantly higher than that of athletes having lower achievements [12-15]. These high levels of fitness are achieved, among others, thanks to strength, strength-speed, and strength-endurance exercise. However, overloading one element of the locomotor system can cause an imbalance between its parts. That is because muscles work together in coordinated patterns when a given type of movement is performed. Some muscle groups have a tendency to initiate the movement, whereas others as- 
sure stability. If these patterns do not function properly, this can cause overloading, resulting in injuries to the locomotor system. If injured, athletes may be unable to compete, and their position in the rankings may be affected significantly. An athlete's predisposition to injury can, nevertheless, be identified by performing an adequate functional assessment. That is why the aim of the current study was to determine the relationship between the degree of functional limitations and the outcomes achieved by judo athletes.

\section{Material and methods}

The participants of the study were 23 judo athletes aged 17-27 years. They had a training experience of at least 8 years. All of the subjects had a champion (dan) rank and were active competitors licensed by the Polish Judo Association. The group included four medallists from European championships and world championships as well as 12 medallists from Polish championships. For the purpose of performing comparative analyses, the judokas were divided into two groups according to their level of achievement. The first group was composed of medallists in international and Polish championships who had one of the top classes in the Polish classification system, that is the championship class or so-called first sport class (medallists), and the second one included athletes who had a lower class, that is the second sport class (non-medallists). In addition, we compared junior (U-20) athletes against senior athletes (Tab. 1).

The main research tool used in the study was the Functional Movement Screen test battery designed by Gray Cook and Lee Burton. It was developed with the aim of performing objective analyses of human movement patterns with reference to functional capacity and with a view to predicting and preventing injuries in athletes. The three-dimensional assessment of movement makes it possible identify abnormalities in kinematic chains and to carry out a comprehensive assessment determining asymmetries and significant functional limitations which are due to inadequate mobility and stability of the locomotor system [16, 17]. The Functional Movement Screen is composed of the following seven exercises which test basic movement patterns: deep squat, hurdle step, in-line lunge, shoulder mobility, active straight leg raise (ASLR), trunk stability push-up, and rotary stability [16, 17].

The performance of each of the tests listed above is assessed on a four-point scale according to pre-defined criteria. The subject can receive from 0 to 3 points for each movement. A subject receives 3 points if the movement was carried out in a correct way, 2 points if it was completed with compensation, 1 point if the subject could not perform the movement, and 0 points if they experienced pain when making the movement or during the pain provocation test. The maximum total number of points is $21[16,17]$.

The FMS test is carried out prior to exercise or warm-up. The assessments are made in two planes - the sagittal plane and the frontal one. The subject performs a given exercise three times, and the rater evaluates the best performance. If any doubts arise concerning the correctness of the performance of a particular movement pattern, the subject is given a lower score. Each side of the body is evaluated separately, if applicable [16, 17].

In addition to the FMS test battery, an original questionnaire designed by the authors was applied. This questionnaire was used to collect biometric data as well as information concerning the participants' training experience, injuries, and pain.

Data concerning the outcomes of the subjects' performance in judo competitions were obtained from the official website of the Polish Judo Association [18]. Only the outcomes achieved in national championships (the Polish National Judo Championship and the Polish Judo Cup) were included in the analysis.

Inter-group differences were determined using the MannWhitney U test. Differences between the results obtained for the left and right side of the body (in the case of bilateral tests) were analysed using the Wilcoxon signed-rank test. Correlations between variables (for example, between the results of the FMS test and age or training experience) were determined using Spearman's rho correlation coefficients. Statistical significance was set at $\mathrm{p} \leq 0.05$.

\section{Results}

The result of the FMS test was significantly higher $(\mathrm{p}<0.05)$ in the group of medallists. Significant differences between medallists and non-medallists were also found for the in-line lunge $(\mathrm{p}<0.05)$ and for the trunk stability push-up $(\mathrm{p}<0.01)$. The differences were nearly statistically significant when it came to the deep squat and shoulder mobility tests. The results obtained for the remaining exercises were similar for both groups (Tab. 2). Scores below 14 points, which were indicative of high susceptibility to injury, were received by two athletes from the group of medallists and eight non-medallists. No relationship was found between age category and the total FMS score or the scores for particular exercises (Tab. 2). Scores equal to or lower than 14

Table 1. Participant characteristics

\begin{tabular}{|c|c|c|c|c|c|}
\hline \multicolumn{2}{|c|}{ Group } & Age [years] & Weight [kg] & $\begin{array}{c}\text { Training experience } \\
\text { [years] }\end{array}$ \\
\hline \multirow{2}{*}{ Level of achievement } & $\begin{array}{c}\text { Medallists } \\
(n=12)\end{array}$ & $21.50 \pm 3.87$ & $86.18 \pm 10.56$ & $183.58 \pm 7.18$ \\
\cline { 2 - 5 } & $\begin{array}{c}\text { Non-medallists } \\
(n=11)\end{array}$ & $22.64 \pm 2.33$ & $73.55 \pm 11.16$ & $173.64 \pm 4.90$ & $13.25 \pm 4.02$ \\
\hline \multirow{2}{*}{ Age } & $\begin{array}{c}\text { Seniors } \\
(n=13)\end{array}$ & $24.46 \pm 1.59$ & $82.54 \pm 12.61$ & $177.08 \pm 7.62$ & $15.15 \pm 3.21$ \\
\cline { 2 - 6 } & $\begin{array}{c}\text { Juniors } \\
(n=10)\end{array}$ & $18.90 \pm 1.56$ & $77.02 \pm 12.06$ & $181.10 \pm 8.07$ \\
\hline
\end{tabular}


Table 2. Functional Movement Screen scores

\begin{tabular}{|c|c|c|c|c|c|c|c|c|}
\hline Group & Deep squat & Hurdle step & $\begin{array}{c}\text { In-line } \\
\text { lunge }\end{array}$ & $\begin{array}{c}\text { Shoulder } \\
\text { mobility }\end{array}$ & $\begin{array}{c}\text { Active straight } \\
\text { leg raise }\end{array}$ & $\begin{array}{c}\text { Trunk stability } \\
\text { push-up }\end{array}$ & $\begin{array}{c}\text { Rotary stability } \\
\text { Total score }\end{array}$ \\
\hline Medallists & 2.00 & 1.92 & $2.17^{*}$ & 2.17 & 1.75 & $3.00^{\star *}$ & 2.25 & $15.25^{*}$ \\
\hline Non-medallists & 2.27 & 1.82 & 1.73 & 1.82 & 1.64 & 2.55 & 2.09 & 13.91 \\
\hline Seniors & 2.08 & 1.69 & 1.92 & 2.00 & 1.62 & 2.69 & 2.23 & 14.23 \\
\hline Juniors & 2.20 & 2.10 & 2.00 & 2.00 & 1.80 & 2.90 & 2.10 & 15.10 \\
\hline
\end{tabular}

Table 3. Functional Movement Screen scores in bilateral tests

\begin{tabular}{|c|c|c|c|c|c|c|c|c|c|c|c|c|}
\hline \multirow[t]{2}{*}{ Group } & \multicolumn{2}{|c|}{ Hurdle step } & \multicolumn{2}{|c|}{ In-line lunge } & \multicolumn{2}{|c|}{ Shoulder mobility } & \multicolumn{2}{|c|}{$\begin{array}{c}\text { Active straight leg } \\
\text { raise }\end{array}$} & \multicolumn{2}{|c|}{ Rotary stability } & \multicolumn{2}{|c|}{ Total score } \\
\hline & $L$ & $\mathrm{R}$ & $\mathrm{L}$ & $\mathrm{R}$ & $\mathrm{L}$ & $\mathrm{R}$ & $\mathrm{L}$ & $\mathrm{R}$ & $\mathrm{L}$ & $\mathrm{R}$ & $\mathrm{L}$ & $\mathrm{R}$ \\
\hline Medallists & 2.17 & 2.08 & 2.17 & 2.25 & 2.42 & 2.33 & 1.83 & 1.83 & 2.25 & 2.17 & 10.83 & 10.67 \\
\hline Non-medallists & 2.00 & 1.82 & 1.91 & 1.91 & $2.27^{* *}$ & 1.82 & 1.82 & 1.82 & 2.27 & 2.18 & 10.27 & 9.55 \\
\hline Seniors & 1.92 & 1.85 & 2.08 & 2.08 & $2.31^{*}$ & 2.00 & 1.85 & 1.77 & 2.23 & 2.31 & 10.38 & 10.00 \\
\hline Juniors & 2.30 & 2.10 & 2.00 & 2.10 & 2.40 & 2.20 & 1.80 & 1.90 & 2.30 & 2.00 & 10.80 & 10.30 \\
\hline
\end{tabular}

Table 4. Number of competitions and matches

\begin{tabular}{|c|c|c|c|c|c|c|c|c|c|}
\hline \multirow{2}{*}{ Group } & \multicolumn{3}{|c|}{$\mathbf{2 0 1 2}$} & \multicolumn{3}{|c|}{2013} & \multicolumn{2}{|c|}{2012 and 2013 } \\
\cline { 2 - 10 } & Competitions & Matches & $\begin{array}{c}\text { Percentage of } \\
\text { matches won }\end{array}$ & Competitions & Matches & $\begin{array}{c}\text { Percentage of } \\
\text { matches won }\end{array}$ & $\begin{array}{c}\text { Competi- } \\
\text { tions }\end{array}$ & $\begin{array}{c}\text { Matches } \\
\begin{array}{c}\text { Percentage of } \\
\text { matches won }\end{array}\end{array}$ \\
\hline Medallists & 4.00 & 15.55 & $68 \%$ & 3.91 & 14.91 & $63 \%$ & 7.91 & 30.45 & $66 \%$ \\
\hline Non-medallists & 3.18 & $7.55^{* *}$ & $23 \%^{* * *}$ & 2.82 & $6.18^{* *}$ & $28 \%^{* *}$ & 6.00 & $13.73^{* *}$ & $27 \% \%^{* * *}$ \\
\hline Seniors & 2.85 & 8.00 & $39 \%$ & 2.62 & 7.62 & $40 \%$ & 5.46 & 15.62 & $39 \%$ \\
\hline Juniors & $4.67^{*}$ & $16.67^{* *}$ & $55 \%$ & $4.44^{*}$ & $14.78^{*}$ & $55 \%$ & $9.11^{* *}$ & $31.44^{* *}$ & $57 \%$ \\
\hline
\end{tabular}

Table 5. Correlations between FMS scores and the number of matches won and lost, number of matches, and proportion of matches won

\begin{tabular}{|c|c|c|c|c|}
\hline Group & Matches won & Matches lost & Matches & Proportion of matches won \\
\hline Whole group & $0.465^{*}$ & 0.011 & 0.365 & $0.462^{*}$ \\
\hline Medallists & -0.333 & -0.182 & -0.301 & 0.114 \\
\hline Non-medallists & 0.319 & 0.004 & 0.023 & 0.318 \\
\hline Seniors & $0.691^{*}$ & -0.026 & 0.437 & $0.662^{*}$ \\
\hline Juniors & -0.018 & 0.342 & 0.093 & -0.018 \\
\hline
\end{tabular}

points were received by six senior judokas and four junior judokas. The lowest score, amounting to 11 points, was achieved by a senior non-medallist. The highest score (18 points) was obtained by a senior medallist.

No major asymmetries were found in the athletes. Significant differences were observed only in the shoulder mobility test in senior judokas $(\mathrm{p}<0.05)$ and non-medallists $(\mathrm{p}<0.01)$ (Tab. 3).

Most of the athletes $(n=12)$ took part in 10 to 20 matches in 2012 and 2013 in the competitions at the level of the Polish National Judo Championship and the Polish Judo Cup. However, some of the judokas $(n=3)$, who competed in the two age categories, had participated in more than 40 fights. There was a significant negative correlation between the number of judo matches completed and age $(\mathrm{r}=-0.725, \mathrm{p}<0.001)$. Junior judokas had taken part in more fights than senior ones $(\mathrm{p}=0.02)$ (Tab. 4).

There was also a positive correlation between the outcome of the FMS test and the number of matches won. This was found for the entire group and for senior judokas (Tab. 5).

\section{Discussion}

Success in judo is achieved by athletes who have a high level of physical fitness, have specific technical and tactical skills, and can react adequately to the actions of their opponents [19- 
21]. However, the main factor that has a bearing on performance outcome in competitions, in particular in combat sports, is the athletes' health condition and their susceptibility to injury. That is why identifying risk factors and implementing preventive measures is important not only in the context of health and quality of life, but also with regard to performance outcomes in sports $[22,23]$. The risk of injury is assessed using different methods, such as the Flamingo Test, the Rotational Test, the Test of Susceptibility to Injuries During Falls, the Double Leg Lowering Manoeuvre, the Core Muscle Strength and Stability Test, the Thomas test, or the Dega test [24-29]. These tests make it possible to assess balance, the range of motion in the joints, or the quality of the movement, that is the ability to perform complex movement patterns. Injuries can have several different causes. Most frequently, however, they are caused by a combination of micro-injuries, overloading of the locomotor system, and inadequate warm-up [5].

The Functional Movement Screen used in the current study is a simple and non-invasive screening test battery that makes it possible to determine the quality of the movement, functional deficits, and the degree of asymmetry in the body. It is applied mostly in athletes (both professionals and amateurs) as well as in many occupational groups where physical preparation plays an important role: it has, for instance, been used to examine soldiers and fire fighters [30-33]. A major advantage of FMS is its high reproducibility. The results can be used to plan prevention - and also rehabilitation, if necessary - in order to address issues with a particular function of the body [34, 35]. The usefulness of FMS is evidenced by a large number of studies where this test has been applied to assess the risk of body injury, the effectiveness of the preventive measures undertaken, or the impact of training on health [36-41].

The results of functional tests most often correlate with particular aspects of physical fitness [42]. The effectiveness of a person's performance in a functional test is, to a certain extent, dependent on ergonomics. Athletes who achieve superior performance outcomes are most often characterised by a low level of functional limitations [43]. This has also been confirmed in the current study, as the judokas from the group of medallists had significantly higher scores in the FMS test battery. In addition, the FMS scores positively correlated with the number of matches won, which may be seen as evidence demonstrating the importance of the quality of movement in achieving favourable outcomes in sports competitions.

The number of factors that impact outcomes in sports is very high, in particular in sports that are refereed, such as combat sports. Although ratings in the Functional Movement Screen test are subjective, it can be a useful tool in assessing not only the risk of body injury but also of the potential of an athlete in a given sports discipline [23, 42]. It thus seems justified to introduce elements of functional assessment in everyday sports practice.

\section{Conclusions}

1. Judo athletes who had better performance outcomes in competitions had higher scores in the FMS test. Therefore, judo training should include reducing functional limitations of the locomotor system and improving movement quality.

2. Most of the professional athletes who participated in the study were characterised by a limited range of motion in the joints. This may be due to an insufficient amount of stret- ching exercises performed as part of the training, and thus this element should be given more attention.

3. Physiotherapy functional assessment tests - which make it possible to implement measures aimed at reducing muscle imbalance, locomotor limitations, or asymmetries - can be useful both in preventing injuries and in improving performance outcomes in sports.

\section{Literature}

1. Amiri-Khorasani M., Kellis E. (2015). Acute effects of different agonist and antagonist stretching arrangements on static and dynamic range of motion. Asian Journal Sports Medicine 6(4), 1-6.

2. Smith C.A., Chimera N.J., Warren M. (2015). Association of Y Balance Test reach asymmetry and injury in division I athletes. Medicine and Science in Sports and Exercise 47(1), 136-141.

3. Szafrański K., Boguszewski D. (2015). Comparison of maximum muscle torque values of extensors and flexors of the knee joint in kickboxing and taekwondo athletes. Journal of Combat Sports and Martial Arts 6(2), 59-62.

4. Garrison G., Westrick R., Johnson M. (2015). Association between the Functional Movement Screen and injury development in college athletes. International Journal of Sports Physical Therapy 10(1), 21-28.

5. Noh J.W., Park B.S., Kim M.Y., Lee L.K., Yang S.M., Lee W.D. et al. (2015). Analysis of combat sports players' injuries according to playing style for sports physiotherapy research. Journal of Physical Therapy Science 27(8), 2425-2430.

6. Sawczyn S., Jagiełło W., Fetisov V.I., Mishchenko V.S. (2015). Dependence of work capacity recovery after strenuous training sessions upon subject predisposition of skilled wrestlers to work under different energy modes. Archives of Budo 11, 197-207.

7. Boguszewski D. (2015). Application of physiotherapeutic methods to support training and post-exercise recovery of combat sports and martial arts contestants. Journal of Combat Sports and Martial Arts 6(2), 85-90.

8. Miladi I., Temfemo A., Mandengue S., Ahmaidi S. (2011). Effect of recovery mode on exercise time to exhaustion, cardiorespiratory responses, and blood lactate after prior, intermittent supramaximal exercise. Journal of Strength and Conditioning Research 25(1), 205-210.

9. Boccolini G., Brazzit A., Bonfanti L., Alberti G. (2013). Using balance training to improve the performance of youth basketball players. Sport Sciences for Health 9, 37-42.

10. Boguszewski D., Mrozek N., Adamczyk J.G., Białoszewski D. (2015). The influence of core stability exercises on functional limitations in female basketball players. Polish Journal of Sports Medicine 31(4), 187-195.

11. Kalina R.M., Kruszewski A., Jagiełło W., Włoch G. (2003). Combat sports propaedeutics - basics of judo. Warszawa: AWF Warszawa. [in Polish]

12. Sterkowicz S., Lech G., Pałka T., Tyka A., SterkowiczPrzybycień K., Szyguła Z. et al. (2011). Body build and body composition vs. physical capacity in young judo contestants compared to untrained subjects. Biology of Sport 28(4), 271-277.

13. Pałka T., Lech G., Tyka A., Sterkowicz-Przybycień K., Sterkowicz S., Cebula A. et al. (2013). Differences in the level of anaerobic and aerobic components of physical capacity in judoists at different age. Archives of Budo 9(3), 195-203. 
14. Sterkowicz-Przybycień K., Ambroży T. (2013). Sexual dimorphism in anthropometric and fitness measurements of top ju-jitsu contestants. Journal of Combat Sports and Martial Arts 4(2), 145-152.

15. Lech G., Pałka T., Tyka A., Jaworski J., Chwała W., Sterkowicz S. et al. (2015). Effect of motor abilities on the course of fight and achievement level in judokas at different age. Archives of Budo. Science of Martial Arts and Extreme Sports 11, 169-179.

16. Cook G., Burton L., Hoogenboom B.J., Voight M. (2014). Functional Movement Screening: The use of fundamental movements as an assessment of function - part 1. International Journal of Sports Physical Therapy 3, 396-409.

17. Cook G., Burton L., Hoogenboom B.J., Voight M. (2014). Functional Movement Screening: The use of fundamental movements as an assessment of function - part 2. International Journal of Sports Physical Therapy 4, 549-563.

18. Polish Judo Association. Retrieved June 21, 2016, from http://web.pzjudo.pl/. [in Polish]

19. Adam M. (2013). A profile of Paweł Nastula's individual technical-tactical preparation. Archives of Budo. Science of Martial Arts and Extreme Sports 9, 69-75.

20. Boguszewski D. (2014). Dynamics of judo contests performed by top world judokas in the years 2008-2012. Journal of Combat Sports and Martial Arts 5(1), 31-35.

21. Adam M., Wolska B. (2016). The general subject technicaltactical profile of the multi-medallist judo athlete Teddy Riner. Archives of Budo. Science of Martial Arts and Extreme Sports 12, 37-44.

22. Okada T., Huxel K.C., Nesser T.W. (2011). Relationship between core stability, functional movement, and performance. Journal of Strength and Conditioning Research 25(1), 252-261.

23. Lockie R.G., Schultz A.B., Jordan C.A., Callaghan S.J., Jeffriess M.D., Luczo T.M. (2015). Can selected Functional Movement Screen assessments be used to identify movement deficiencies that could affect multidirectional speed and jump performance? Journal of Strength and Conditioning Research 29(1), 195-205.

24. Ladeira C.E., Hess L., Galin B., Fradera S., Harkness M.A. (2005). Validation of an abdominal muscle strength test with dynamometry. Journal of Strength and Conditioning Research 19(4), 925-930.

25. Kalina R.M., Barczyński B., Klukowski K., Langfort J., Gąsienica-Walczak B. (2011). The method to evaluate the susceptibility of injuries during the fall - validation procedure of the specific motor test. Archives of Budo 7(4), 201215.

26. Kalina R.M., Jagiełło W., Barczyński B.J. (2013). The method to evaluate the body balance disturbation tolerance skills validation procedure of the Rotational Test. Archives of Budo 9(1), 59-80.

27. Mosler D. (2015). Validity and reliability of non-apparatus and quasi apparatus flexibility tests - verification during health-related training based on judo. Archives of Budo. Science of Martial Arts and Extreme Sports 11, 123-133.

28. Mosler D. (2015). Usability of non-apparatus and quasi apparatus flexibility tests based on self-perception participants in health-related judo training. Archives of Budo. Science of Martial Arts and Extreme Sports 11, 189-197.

29. Boguszewski D., Adamczyk J.G., Buda M., Kłoda M., Białoszewski D. (2016). The use of functional tests to assess risk of injuries in judokas. Archives of Budo. Science of Martial Arts and Extreme Sports 12, 57-62.
30. Peate W.F., Bates G., Lunda K., Francis S., Bellamy K. (2007). Core strength: A new model for injury prediction and prevention. Journal of Occupational Medicine and Toxicology 2, 3. DOI: 10.1186/1745-6673-2-3.

31. Lisman P., O’Connor F.G., Deuster P.A., Knapik J.J. (2013). Functional Movement Screen and Aerobic Fitness Predict Injuries in Military Training. Medicine and Science in Sports and Exercise 45(4), 636-643.

32. Kodesh E., Shargal E., Kislev-Cohen R., Funk S., Dorfman L., Samuelly G. et al. (2015). Examination of the effectiveness of predictors for musculoskeletal injuries in female soldiers. Journal of Sports Science and Medicine 14, 515-521.

33. Bock C., Stierli M., Hinton B. (2016). The Functional Movement Screen as a predictor of police recruit occupational task performance. Journal of Bodywork and Movement Therapies 20, 310-315.

34. Schneiders A.G., Davidsson A., Hörman E., Sullivan S.J. (2011). Functional Movement Screen normative values in a young, active population. International Journal of Sports Physical Therapy 6(2), 75-82.

35. Teyhen D., Shaffer S., Lorenson C. (2012). The functional movement screen: A reliability study. Journal of Orthopaedic and Sports Physical Therapy 42(6), 530-540.

36. Letafatkar A., Hadadnezhad M., Shojaedin S., Mohamadi E. (2014). Relationship between Functional Movement Screening score and history of injury. International Journal of Sports Physical Therapy 1, 21-27.

37. Słodownik R., Ogonowska-Słodownik A., MorgulecAdamowicz N. (2014). Fundamental movement patterns and potential risk of injuries in $1^{\text {st }}$ and $2^{\text {nd }}$ division Polish handball players. Trends in Sport Sciences 3(21), 145-151.

38. Sprague P., Mokha M., Gatens D. (2014). The relationship between glenohumeral joint total rotational range of motion and the Functional Movement Screen shoulder mobility test. International Journal of Sports Physical Therapy 9(5), 657-664.

39. Adamczyk J.G., Boguszewski D., Białoszewski D. (2015). Functional assessment of male track and field runners through Functional Movement Screen test. Medicina dello Sport 68(4), 563-575.

40. Boguszewski D., Jakubowska K.J., Adamczyk J.G., Białoszewski D. (2015). The assessment of movement patterns of children practicing karate using the Functional Movement Screen test. Journal of Combat Sports and Martial Arts 6(1), 21-26.

41. Clifton D., Grooms D., Onate J. (2015). Overhead deep squat performance predicts Functional Movement Screen ${ }^{\mathrm{TM}}$ score. International Journal of Sports Physical Therapy 10(5), 622-627.

42. Lockie R., Schultz A., Callaghan S. (2015). A preliminary investigation into the relationship between Functional Movement Screen scores and athletic physical performance in female team sport athletes. Biology of Sport 32, 41-51.

43. Adamczyk J.G., Pepłowski M., Boguszewski D., Białoszewski D. (2012). Functional evaluation of competitors practising weightlifting with using Functional Movement Screen Test. Polish Journal of Sports Medicine 28(4), 267-276.

Submitted: October 17, 2016

Accepted: June 9, 2017 